\title{
Reflexiones acerca de la prudencia en Kant*
}

\author{
REINHARD BRANDT \\ Universidad de Marburgo
}

Resumen. Kant analiza el tema de la prudencia en contextos muy diferentes. Su antropología pragmática es una doctrina de la prudencia; un resumen de las lecciones sobre antropología impartidas desde 1772-1773 hasta 1795-1796 fueron publicadas en 1798. En su filosofía moral la prudencia aparece bajo aspectos muy diversos. En primer lugar es un oponente de la pura moralidad que trata de guiar la vida humana concediendo prioridad al imperativo categórico; sin embargo, por otro lado, supone un deber moral el cultivar la prudencia como una facultad humana capaz de introducir cambios pragmáticos en nuestra vida. Y, en tercer lugar, la filosofía moral muestra la posibilidad de una convergencia entre moralidad y prudencia; cabe encontrar esto en la concepción kantiana del sumo bien en la ética y en la filosofía política, en la idea de que las acciones morales se mostrarán al volverse más prudentes. Otro aspecto relevante de la reflexión kantiana sobre la prudencia es el problema de la libertad; en la Crítica de la razón práctica, la ley moral es la condición necesaria y suficiente de la libertad; pero entonces se plantea la cuestión de si las acciones prudentes pueden ser libres o son meros productos de la determinación del sentido interno.
ABSTRACT. Kant discusses prudence in many different contexts. His pragmatic anthropology is a doctrine of prudence; Kant lectured on anthropology from 1772-1773 until 1795-1796 and published a resumee of those lectures in 1798. In his moral philosophy, prudence appear under various aspects. First, it is an opponent to pure morality, trying to guide human life instead of conceding primacy to the categorical imperative; but on the other hand it is a moral duty to cultivate prudence as an human faculty which enables us to master pragmatic challenges in our life. And, thirdly, moral philosophy shows the possibility of a convergence of morality and prudence; you can find this in Kant's conception of the highest good in ethics and in political philosophy, in the idea, that moral actions will show themselves to be the most prudent. Another important aspect of Kant's philosophy of prudence is the problem of freedom; in the Critique of Practical Reason the moral law is the necessary and sufficient condition of freedom; but then raises the question about whether prudent actions can be free or are merely the products of the determination of the inner sense.

* Versión castellana de María Xesus Vázquez Loberías. 
Lo que es la prudencia lo sabe cualquiera. Toda lengua en cada época y en cada pueblo tiene una palabra para ello, que concuerda más o menos con las palabras correspondientes de todas las otras lenguas. Esto mismo se puede decir de su antónimo, la necedad, y también acerca de las palabras o los conceptos colindantes tales como la sabiduría y la astucia. Astuto es el que, sin otras virtudes, sólo es prudente momentáneamente; sabio, el que aplica la prudencia a su vida entera $y$, en todas las decisiones, concede prioridad a la moral. Es frecuente, por lo demás, en todos los pueblos, caracterizar como prudente en casos particulares el comportamiento de los animales superiores o incluso el de una determinada especie: el zorro es manifiestamente prudente, el asno necio. Los zoólogos modernos nos dejan maravillados en lo tocante a lo prudente que resulta el comportamiento de algunos animales. Sucintamente: la palabra o el concepto de la prudencia forma parte de nuestra comprensión elemental de nosotros mismos y del mundo; no se trata de un término particular de la filosofía y, en una primera impresión, no resulta plausible el que los fílósofos se hayan ocupado del concepto de todos conocido de la prudencia. ¿No se generarán entonces problemas artificiales? En lo sucesivo deberá mostrarse en qué complejas meditaciones se puede incurrir cuando se considera ponderadamente la prudencia en la comprensión de sí mismo y del mundo por parte del ser humano. Tal es, de manera ejemplar, el caso de Kant.

El tema de la «prudencia» es particularmente complejo y sinuoso, debido a que Kant no escribió ningún tratado aparte sobre la prudencia; así pues, podremos rastrear el hilo candente tan sólo en otra urdimbre, en particular, naturalmente, en la filosofía moral kantiana. El lector prudente deberá armarse de paciencia para poder seguir los laberínticos repliegues de nuestras explicaciones.

La prudencia, para Kant, se encuentra sometida al veto de la moral; lo que es prudente pero no moral es eliminado de modo soberano e incondicional, sea todo lo prudente que quiera. La moral es un asunto de la razón pura práctica, ésta es, por excelencia, la instancia suprema del ser humano y de todo ser racional en general, es decir, que no está condicionada ni limitada desde el punto de vista antropológico. Cuando interviene, lo hace con necesidad absoluta, categórica. La prudencia, la agudeza y el ingenio se encuentran, por el contrario, arraigados en la aspiración humana a la felicidad. La prudencia dispensa consejos, no manda ni prohíbe categóricamente, sino hipotéticamente: «Si tú deseas efectivamente $\mathrm{Z}$ y no tan sólo de una manera vaga, entonces haz $-\mathrm{u}$ omite $-\mathrm{X}$ e $\mathrm{Y} \gg$. La prudencia no conoce con exactitud cómo saldrá todo, puesto que los seres humanos están insoslayablemente abocados a procurar su felicidad siguiendo sus inclinaciones, pero nadie puede decir cabalmente en qué consiste el pretendido estado de felicidad («Glückseligkeit», en griego «eudaimonía»). En relación con este estado de felicidad parece tener validez lo mismo que escribe Kant con respecto a la 
felicidad (Glück)* qua «fortuna» en la Crítica de la razón pura $(\mathrm{KrV}$, 1781) ${ }^{1}$ : «Pero hay también conceptos usurpados, como, por ejemplo, $f e$ licidad, destino, que, a pesar de circular tolerados por casi todo el mundo», nadie podría, se dice a continuación, proporcionar una deducción de los mismos, «ya que no se puede introducir ninguna justificación clara, ni desde la experiencia ni desde la razón, para poner de manifiesto la legitimidad de su empleo» (A 84). Aunque el objetivo de la felicidad, para cuya consecución proporciona la prudencia sus consejos en imperativos hipotéticos, se encuentra en el horizonte de la vida humana de un modo necesario pero solamente indeterminado y cambiante, existe un amplio campo de la prudencia en la acción pública y privada, que Kant elucida en su «Antropología pragmática». Ésta es una doctrina empírica de la prudencia, que, debido a su fundamento en la naturaleza humana, es decir, en la mera experiencia, no forma parte propiamente de la filosofía crítica en tanto que conocimiento racional a partir de conceptos. En la filosofía, en cambio, se discute el interno carácter de deber (Soll-Character) de los imperativos hipotéticos pragmáticos con sus propuestas de la prudencia en contraste con el imperativo categórico.

La prudencia está sometida al veto de la moral; posee, sin embargo, la inclinación natural a sustraerse a dicho veto y arrogarse a sí misma las decisiones últimas, trastoca el orden racional partiendo de su propia naturaleza. La prudencia es, por ello, el enemigo natural de la razón pura práctica, que se ve ante el deber de someter la prudencia, al servicio de la aspiración a la felicidad, a las decisiones de la moral. Aquí se encuentra la zona de conflicto entre la moral y la prudencia, entre el mandato categórico y las instrucciones de la astucia, que quiere ser más perspicaz y se sitúa en primer plano. Éste es el campo de batalla entre el deber y la inclinación, que el ser humano, el centauro, no puede abandonar nunca.

Por otra parte, existen ámbitos en los que la moral y la prudencia son compatibles; la moral no exige a la manera estoica que se haga retroceder a las inclinaciones hasta la apatía; al contrario, cuenta el cultivo de la propia prudencia entre sus deberes imperfectos**. Por lo demás, la prudencia y la moral al final, en general, deben converger, puesto que, tanto en la esfera privada como en la pública, debe probarse que seguir los mandatos de la vir-

* La palabra Gliick en alemán significa tanto «fortuna» como «felicidad» (N. T.).

I Se cita a Kant (salvo en la traducción de un escrito latino) siguiendo la edición de la Academia de las Ciencias (Akademie-Ausgabe), Gesammelte Schriften, Berlín, 1900 y ss.; sólo en el caso de la Crítica de la razón pura prefiero, debido a la cómoda estampación de las ediciones A y B, la de Felix Meiner, Hamburgo, 1998. (En castellano se cita siguiendo la traducción de Pedro Ribas, Crítica de la razón pura, Madrid, Alfaguara, 1978, 1995; en el texto principal, en este caso y en los sucesivos, se mantiene la referencia de la paginación de la primera edición proporcionada por el autor. N.T.).

** Se traduce el término «weite Pflichten» por «deberes imperfectos» siguiendo la edición castellana de Adela Cortina Orts, Metafisica de las costumbres, Madrid, Tecnos, 1989, 1994 (N. T.). 
tud y del derecho no solamente es moral, sino además prudente. Se abre aquí un amplio dominio en el que la moral y la prudencia no se encuentran en un conflicto irremisible, sino que son compatibles e incluso se necesitan la una a la otra.

Un problema particular de la filosofía moral crítica estriba en su consecuencia interna de absorber la libertad. Libertad y moral son conceptos intercambiables, de modo que la libertad hace posible el imperativo categórico y viceversa, el imperativo categórico es la condición necesaria y suficiente de la libertad. Pero en qué se queda la libertad de la que somos conscientes en las propias acciones y juicios indiferentes en relación con la moralidad? ¿Es la acción prudente como tal libre o cae en el determinismo? ¿O bien cae todo actuar y juzgar humano bajo las condiciones de la moral y con ello de la libertad, porque todo lo que hacemos está permitido o prohibido moralmente?

Si después de estas sugerencias se pretende localizar el tema de la «prudencia» en los escritos de Kant, se pensará en primera instancia en la «Antropología en sentido pragmático», transmitida en forma de apuntes de lecciones universitarias desde 1772-1773 hasta los años noventa ${ }^{2}$, y con una publicación independiente (1798). El tema central de esta antropología es la acción prudente en la sociedad, adecuada a la marcha del mundo. Tenemos, en segundo lugar, el imperativo de la prudencia, que, como tal, no es tematizado en la antropología, pero que ocupa un lugar importante desde el punto de vista sistemático en la filosofía práctica de Kant. Nos ocuparemos en primer lugar (1) de estos dos ámbitos. Sigue a continuación (2) la confrontación de la prudencia y la moralidad; ¿qué aspecto presenta el palmario conflicto entre ambas? En tercer lugar (3) nos dedicaremos a la exposición de la compatibilidad entre la prudencia y la moral, y en cuarto lugar (4) a la cuestión: ¿es la acción prudente bajo las premisas de la filosofía crítica un comportamiento libre?

Al igual que otras piezas de la teoría, la diversificada doctrina kantiana de la prudencia se encuentra en conexión con la reflexión tradicional acerca de «phronesis», «prudentia», «prudence». Se localiza en alternativas predeterminadas y en innovaciones posibles gracias a una tradición de proyectos previos y de sus pro y contra. Es necesario, por lo tanto, comprender la doctrina específica de la prudencia a partir de su genealogía, puesto que en esa genealogía y contra esa genealogía desarrolla sus pertinaces hechos y fundamentos y precisamente ella sirve para reconocer, para saber exactamente con qué objeto se formula una exigencia de validez.

Un primer frente lo ofrece la «prudencia» en el sistema de las cuatro virtudes cardinales. Debido a determinadas premisas, Kant no podía en ningún caso adoptar este sistema. La explicitación de estas premisas nos conduce

${ }^{2}$ Las lecciones de antropología están editadas en el volumen XXV de Kant, 1900 y ss. 
así a la parte principal de la doctrina kantiana de la prudencia, tanto en el marco de la ética y la política, como en el de la antropología. Las virtudes cardinales, y con ello la localización filosófica originaria de la prudencia, se requieren para la delimitación en una investigación genealógica. La teoría propia de Kant no recoge la doctrina de las virtudes cardinales, si bien pretende salvaguardar su contenido.

\section{LAS CUATRO VIRTUDES CARDINALES}

La Politeia de Platón (aprox. 375 a. C.) instruye de la mejor manera acerca de las virtudes cardinales de la «temperantia», «fortitudo», «prudentia» e «iustitia». Estas virtudes representan un bien activo adecuado a la naturaleza y a la razón, que apunta en diversas direcciones, un bien tanto del individuo singular como de la polis isomorfa. La peculiar estructura formal consiste en que no pueden intercambiarse las posiciones y que la cuarta virtud, la justicia, conforme al esquema 1,2, 3, / 4 no conlleva ninguna ampliación desde el punto de vista del contenido, sino que es el resultado y el fundamento de la consonancia de las tres virtudes precedentes. De acuerdo con dicho ordenamiento la sociedad justa se divide en tres estamentos, que se perfilan con las expresiones: productores, guardianes, sabios (plough, sword, book). Existen, análogamente, tres partes del alma individual en la forma de facultad de desear, valentía o voluntad y sabiduría. Se trata de una mezcla ponderada de factores y fuerzas singulares de tipo psicológico y social, cuya sintonía funcional indica que el individuo en cuestión, o la correspondiente polis, es justo y bueno. Para las virtudes singulares esto significa a priori que ninguna de ellas puede darse realmente si no se encuentra en su necesario emplazamiento en el entramado de las virtudes. No hay, por tanto, efectiva prudencia que no esté en armonía con la modestia, la valentía y también con la justicia. Alguien puede ser astuto en la planificación de una acción cobarde, pero con su astucia no pone en práctica la virtud de la prudencia. El criterio de una acción prudente es muy sencillo: debe encajar en la constelación de la justicia. Los seres humanos pueden confundirse acerca de la verdadera condición de las acciones prudentes o imprudentes, pero ello no cambia nada con respecto a los indicios orientativos que desarrolla Platón. Se aprecia al punto que en esta ordenación armoniosa es posible un más y un menos, puesto que pueden darse niveles intermedios entre la consonancia ideal y el completo desbarajuste anímico y social; la condición de abandono interior y social es injusta. El déspota envidiado por la masa es, aun con toda la plenitud de su poder y con toda la riqueza, un gobernante injusto, su alma está desgarrada y es, por consiguiente, infeliz. La ciudad justa, por el contrario, no necesita de un gobernante, porque se preserva a sí misma en la consonancia de las tres formaciones sociales bajo la dirección del primer esta- 
mento: su autogobierno es la justicia. Lo mismo rige en la esfera interna del ser humano.

No se necesita ninguna aclaración prolija para reconocer que la doctrina kantiana de la virtud y de la prudencia no supone una continuación inmediata de la platónica, es suficiente con el tópico de la ética formal y el rigorismo para poner de manifiesto la distancia. Nunca podría hallarse en el caso de Platón o Aristóteles una frase similar a la famosa formulación introductoria a la Fundamentación para una metafísica de las costumbres (GMS, 1785): «No es posible pensar nada dentro del mundo, ni después de todo tampoco fuera del mismo, que pueda ser tenido por bueno sin restricción alguna, salvo una buena voluntad» (IV, 393) ${ }^{3}$. La voluntad no se coloca aquí ni bajo la condición de un conocimiento precedente de aquello que propiamente se quiere, ni se inserta en un orden armonioso de un entramado de tipo social y anímico. Este conocimiento precedente, que guía a la voluntad en conformidad con ella, sería la «prudencia» en la doctrina platónica de las virtudes. Con Kant, sin embargo, la prudencia es relegada del orden ético fundamental. Por lo demás, la formulación kantiana es expresión de una doctrina moral rigorista que no conoce tonalidades intermedias entre lo bueno y lo no-bueno, sino que coloca a cada uno de los actos de la voluntad ante la alternativa de lo bueno o lo no-bueno. Tendremos que investigar en qué se fundamenta, desde un punto de vista histórico y sistemático, la completa metamorfosis de la polis y de la psique.

\section{PRUDENCIA VERSUS MORAL ANTES DE KANT}

Una antorcha del nuevo orden moderno es la doctrina de la prudencia en $E l$ Príncipe, de Nicolás Maquiavelo (1469-1527). Sin entrar en el terreno de la filosofía ni aun en el de la teoría, Maquiavelo destruye desde fuera las estructuras cuidadosamente fundamentadas, con la pretensión de poder de la praxis habitual y de sus necesidades inherentes. Aquí la «prudencia» se escinde del contexto de un orden social y anímico armónico y es refrendada por el imperialista florentino como la única virtud que cuenta desde el punto de vista político. La prudencia se relaciona ahora únicamente con el conocimiento, indiferente con respecto al valor, acerca de los mejores medios para la realización de cualesquiera fines del comportamiento humano, a su vez máximamente eficientes. El maquiavelismo de Maquiavelo, no obstante, es imprudente de facto al menos en dos aspectos: por una parte, se dejan de lado las cuestiones económicas $\mathrm{y}$, por otra, no se investiga cómo puede el

\footnotetext{
3 Pierre Aubenque ofrece una comparación de la doctrina de la prudencia de Aristóteles y de Kant en La prudence chez Kant, Aubenque, 1986, pp. 186-212. [En castellano se cita siguiendo la traducción de Roberto R. Aramayo, La fundamentación para una metafisica de las costumbres, Madrid, Alianza Editorial, 2002 (N. T.)].
} 
estado del «príncipe» procurarse a la larga reconocimiento y seguridad diplomática en el contexto de los poderes externos ${ }^{4}$.

Niccolò, Old Nick, Machiavelli, ha colocado a la prudencia bajo sospecha, o al menos la ha llevado al descrédito. Volveremos a encontrar el maquiavelismo de la mera política prudencial en la contraposición kantiana de política moral y la severamente reprobada moral política. Pero ocupémonos por de pronto del enemigo más significativo de Maquiavelo: Thomas Hobbes (1588-1679).

Con el oponente de la imprudente doctrina de la prudencia de Maquiavelo, con Thomas Hobbes, regresamos a la elaboración teórica y con ello a la vez a uno de los fundamentos de la doctrina kantiana de la prudencia. La prudencia, aislada y monopolizada por Maquiavelo, es desterrada de la fundamentación teórica del estado. Esto debe citarse pormenorizadamente: "Por "filosofía" se entiende el conocimiento adquirido por razonamiento, que parte del modo en que una cosa se genera para llegar a sus propiedades; o que parte de las propiedades para llegar a algún modo posible de explicar cómo se generó dicha cosa, a fin de producir, hasta donde lo permita el asunto y la capacidad humana, esos efectos que la vida humana requiera. Así, el geómetra, partiendo de la construcción de figuras, descubre muchas propiedades de las mismas [...] Así, el astrónomo, partiendo de la salida, de la puesta y del movimiento del sol y de las estrellas en las diversas regiones celestes, descubre las causas del día y de la noche [...] Y de manera semejante ocurre con las demás ciencias [particularmente la teoría del estado]. De esta definición resulta evidente que no debemos considerar como parte de la filosofía el conocimiento original llamado experiencia, en el cual se basa la prudencia. Pues no se consigue mediante razonamiento, sino que se da tanto en los brutos como en el hombre» ${ }^{5}$.

Con Hobbes se inicia el equipamiento de la sociedad europea y su preparación y rectificación filosófica, de modo que el gobierno de los estados, legitimado históricamente de forma necesaria, se sustituye por el principio de la originaria libertad e igualdad de derechos de los ciudadanos, junto con la desigualdad económica, que se traslada al ámbito de lo privado. La justicia se convierte en una cuestión de poder judicial, la prudencia se traslada a la gestión privada de la economía, y moderado y valiente séalo cada uno según su propio gusto, esto forma parte de las «small morals». La filosofía del derecho hobbesiana refuerza una tendencia presente ya en el derecho romano, la tendencia a la separación de lo interior y lo exterior; el estado representa solamente el forum externum y se declara incompetente para vigilar y juzgar el talante de los ciudadanos. Mientras que el estado platónico y

\footnotetext{
4 Acerca del concepto alternativo de prudencia política en Justus Lipsius, cf. Wiedemann, 2000.

5 Hobbes, Leviatán, cap. 46, 1966, p. 507. [En castellano se cita siguiendo la traducción de Carlos Mellizo, Leviatán: la materia, forma y poder de un Estado eclesiástico y civil, 2 vols., Barcelona, Altaya, 1997, p. 510 (N. T.)].
} 
aristotélico se consideraba como la entidad educadora de los buenos seres humanos y ciudadanos, el estado moderno se ubica en la esfera de las acciones exteriores y no pregunta por el talante más que en los dominios secundarios de la escolarización y de la investigación de motivos e intenciones en el caso de la transgresión de la ley. El ciudadano se encuentra frente a la exterioridad de un estado que ya no lo reproduce isomórficamente, de modo que se encuentra a sí mismo en la polis, como en el caso de Platón. La interna compenetración del ciudadano y del estado es sustituida por la salvaguardia negativa ante posibles lesiones; en el interior del estado la polis cede así su puesto a la policía.

El decisivo complemento de los conceptos de ciudadano libre e igual con la licencia de la desigualdad económica lo lleva a cabo Locke en su Second Treatise of Government (1690), decisivo porque aquí el monstruo de un poder absoluto que se sustrae al principio de la libertad y la igualdad, siendo «legibus absolutus», es declarado como «outlaw»; la sociedad en su conjunto se constituye y subsiste de conformidad con los principios del derecho natural y Locke muestra que esto es necesario desde el punto de vista jurídico y que es políticamente posible. Es inherente a la libertad el no estar sometido a ley alguna que no emane de la propia voluntad libre; con ello se dibuja - en un principio sólo vagamente - la doctrina de la división de poderes. Locke regresa así a Platón en un respecto que adelanta el porvenir: no hay gobernante alguno que no esté ligado al sistema de obligaciones de la sociedad. Por lo demás, el orden de las virtudes cardinales se ha vuelto irrelevante.

Entre el avituallamiento conceptual de la filosofía práctica de los inicios de la edad moderna figura una componente que no ha sido mencionada hasta ahora, pero que guarda relación con el profundo efecto de la recepción europea global y también americana de las mencionadas teorías: la filosofía de los estoicos y de los epicúreos. Estas escuelas, que apenas habían ejercido influencia durante la Edad Media, ganan paulatinamente en significación durante el Renacimiento. Epicuro, y tras él Lucrecio, retoman una doctrina vigente ya en la sofística acerca del contrato social, conforme a la cual los ciudadanos contraen prudentemente el deber recíproco de no infligirse mutuamente daño alguno. La figura moderna del contrato podría enlazar con ambos atomistas, asimismo significativos para la filosofía natural. Más importante aún es la influencia de la stoa. A través de la misma se hace posible la unión del imperio legal del estado con la razón, de modo que el estado, que corresponde al contrato, comprensible aún con un enfoque epicúreo, se puede integrar en una razón divina que se extiende al mundo entero. El estado puede configurarse externamente de tal manera que se ocupe únicamente de la compatibilidad de las acciones externas de sus ciudadanos; la recta ratio, sin embargo, que conduce a él como redención del insostenible estado natural, no equivale al entendimiento instrumental con su capaci- 
dad para resolver problemas, del que dispone también un pueblo de demonios, sino que equivale a la razón en tanto que instancia suprema del conocimiento y de la acción en los seres humanos. Esta razón es en principio idéntica al logos divino. El ciudadano obedece las leyes partiendo de la libertad, es decir, desde la libre comprensión de la necesidad de un orden legal. En la stoa la prudencia tampoco se encuentra ya encuadrada en una ordenación armónica de las virtudes cardinales, sino que se convierte en un principio gnoseológico que conduce a los sabios a la completa integración en la naturaleza y con ello al mismo tiempo en el orden estatal (al menos en principio). Al contrario que en la filosofía práctica de Aristóteles y Platón, la última stoa no deja lugar para un más o menos de las virtudes, sino que opera con un «todo o nada», o bien cumplimos la ley o la transgredimos, tertium non datur. Sobre la base de este rigorismo de los deberes, el neoestoicismo del siglo XVII pudo proporcionar bienvenidas contribuciones a las medidas disciplinarias estatales y anímicas. La prudencia es la comprensión de la necesidad, a la que solamente se sustrae el necio.

\section{LA PRUDENCIA EN KANT}

\section{Antropología pragmática e imperativo hipotético}

\section{a) Antropología pragmática}

En el semestre de invierno de 1772-1773 Kant inauguró su curso de antropología, que impartiría regularmente hasta el semestre de invierno de 17951796. Luego de haber concebido la lección en principio tan sólo como una puesta a salvo de la psicología empírica de la Metafísica de Baumgarten (porque lo empírico no pertenece propiamente a la filosofía), la reconvirtió durante la primera mitad de los años setenta en una doctrina pragmática, orientada a cuestiones vitales prácticas. A mediados de los años setenta encontramos la siguiente declaración: «La segunda parte del conocimiento mundano es el conocimiento del ser humano, que se toma en consideración en la medida en que su conocimiento nos interesa para la vida. Es decir, el ser humano se estudia no especulativamente, sino para aplicar su conocimiento pragmáticamente, conforme a reglas de la prudencia, y esto es la antropología [...] así debemos estudiar a la humanidad no psicológica o especulativamente, sino pragmáticamente, puesto que todas las doctrinas pragmáticas son doctrinas de la prudencia [...] ya que nosotros estudiamos al ser humano para llegar a ser más prudentes, de modo que la prudencia se convierte en ciencia» (XXV, 470-471). La primera parte del conocimiento mundano es la geografía física, tema también de una lección que Kant subsume bajo la rúbrica de lo pragmático. El conocimiento mundano «es el que 
sirve para proporcionar a todas las ciencias y habilidades ya adquiridas la dimensión de lo pragmático, mediante la cual no son útiles solamente para la escuela, sino para la vida, y mediante las cuales el recién egresado se introduce en el escenario de su destino, es decir, en el mundo. Se encuentra aquí un doble campo ante él con respecto al cual necesita un boceto preliminar, para poder ordenar en él conforme a reglas todas las experiencias futuras, a saber: la naturaleza y el hombre» (II, 443).

El oyente de la lección debía ser sucintamente informado acerca de sí mismo y de la sociedad humana para poder moverse en el mundo prudente y provechosamente. Tras frecuentar la lección sabría de qué facultades anímicas fundamentales se encuentra en principio provisto el ser humano: facultad de conocer, sentimiento de placer y displacer, y facultad de desear; se le aleccionaba acerca de la fortaleza y la debilidad, de la condición sana y patológica de estas facultades. Acto seguido se exponían en la segunda parte de la lección las características específicas de determinados individuos con relación a sus respectivas naturalezas, su temperamento, su género, la raza, la nación y el carácter, lo que de nuevo concierne en general a todos los seres humanos. Se presentaban aquí alternativas en distribuciones duales (masculino o femenino), con cuatro posibilidades (cuatro temperamentos, cuatro razas) o en sistemas abiertos, como, por ejemplo, la nación, a las que pertenecerían todos. La lección culmina al final con la elucidación del carácter del género humano y de su destino, adquiriendo así un perfil moral que rebasa toda prudencia vital. El pasaje decisivo dice lo siguiente, en la versión publicada como libro en 1798: «La suma de la antropología pragmática respecto al destino del hombre y a la característica de su desarrollo es la siguiente. El hombre está destinado, por su razón, a estar en una sociedad con hombres, y en ella, y por medio de las artes y las ciencias, a cultivarse, a civilizarse y a moralizarse, por grande que pueda ser su propensión animal a abandonarse pasivamente a los incentivos de la comodidad y buena vida que él llama felicidad, y en hacerse activamente, en lucha con los obstáculos que le depare lo rudo de su naturaleza, digno de la humanidad» (VII, 324-325)*. Se ve cómo se abandona aquí la perspectiva de la mera doctrina de la prudencia y se ingresa en el terreno de la filosofía moral, puesto que la determinación racional ya no es cosa del entendimiento o de la razón instrumental, que se dirige reflexivamente a los medios para fines vitales empíricos, sino que es cosa de la razón pura práctica y con ello de la instancia suprema de la que dispone en general el ser humano. Kant bosqueja este trascender con respecto a lo meramente pragmático tal vez ya en el prólogo del escrito: «El conocimiento fisiológico del hombre trata de investigar lo que la naturaleza hace del hombre; el pragmático lo que él mismo, como ser que obra libremente, hace, o puede y debe hacer, de sí mismo» (VII, 119). «Debe» (soll),

* En castellano se cita siguiendo la traducción de José Gaos, La antropología en sentido pragmático, Madrid, Alianza Editorial, 1991 (1935) (N. T.). 
éste es el ascenso hacia la moral, a la vez que permanece como un tema de la antropología, puesto que el ser humano dispone como tal no solamente de una razón instrumental de la prudencia, sino también de la razón pura práctica: ella es un atributo de nuestro género.

Dentro de la antropología pragmática misma se ofrecen al lector y al oyente ocasiones diversas de hacerse más prudente. Se necesita solamente dejar de hacer todo aquello que se expone con detalle y suficiencia bajo los epígrafes «Demencia y estupidez» y «Diferencia entre la insensatez y la necedad» (XXV, 109-118; cf. también las explicaciones correspondientes en los restantes ejemplares de lecciones); el que omite todas las estupideces, insensateces y necedades observadas y catalogadas por Kant es ya eminentemente un hombre prudente. De manera positiva, hay que enseñorearse de lo que aparece bajo los epígrafes «Ingenio y agudeza» (XXV, 132-139), tal vez inclusive de las explicaciones «Acerca de la risa» (XXV, 139-146). Pero nos encontramos también con la mirada escéptica y distante, que hace que se considere la vida en su conjunto como carente de finalidad y de sentido. El 19 de diciembre de 1798, Goethe escribe a C. G. Voigt: «Con todo lo excelente, agudo, delicioso, con lo que nuestro viejo maestro se iguala siempre a sí mismo, me parece [el libro de Kant sobre antropología] en muchos pasajes obtuso y en muchos más aliberal. Un hombre sabio no debería utilizar tan a menudo la palabra necio [...]» ${ }^{6}$. Kant no quiere, como sabio, paliar ni encubrir, sino, como psicoanalista, poner de manifiesto las fijaciones de los seres humanos, inclusive las de los poetas y pensadores. Desarrolla un panorama de situaciones vitales lo más realista posible y prepara al hombre activo para su actividad futura y para el trato prudente consigo mismo y con los demás, y lo que importa ahí en particular no es construir sobre la fortaleza, sino contar con las debilidades.

En la Crítica de la razón pura Kant caracteriza del siguiente modo el ámbito y la competencia de la doctrina de la prudencia, tal como se amplía en la antropología pragmática: "Práctico" es todo lo que es posible mediante libertad. Pero si las condiciones del ejercicio de nuestra voluntad libre son empíricas, la razón no puede tener a este respecto más que un uso regulador ni servir más que para llevar a cabo la unidad de las leyes empíricas; así, por ejemplo, en la doctrina de la prudencia, sirve para unificar todos los fines que nos proponen nuestras inclinaciones en uno solo, la felicidad; la coordinación de los medios para conseguirla constituye toda la tarea de la razón. De ahí que las únicas leyes que ésta puede suministrarnos sean no leyes puras y enteramente determinadas a priori por la razón, sino leyes pragmáticas de la conducta libre encaminada a la consecución de los fines que los sentidos nos recomiendan» ( $K r V$, A 800; cf. también VI, 58). La prudencia, por tanto, es cosa de la razón, en la medida en que ésta adopta una función

${ }^{6}$ Goethe, edición de Weimar, IV, vol. 13, 1887-1919, p. 347. 
subsidiaria, y, en tanto que instrumental, señala los medios para los fines de la felicidad y lleva a cabo su unificación. No se trata de la razón pura práctica, sino solamente de la razón práctica, pero que a pesar de todo es libre, aun siendo, como dice Hume: «slave of the passions» ${ }^{7}$. Su «debe» es condicionado, sus imperativos son imperativos de naturaleza hipotética, dice la Fundamentación para una metafísica de las costumbres.

\section{b) Imperativos hipotéticos: consejos de la prudencia}

«Todos los imperativos mandan hipotética o categóricamente» (IV, 414). Los primeros se dividen, por una parte, en los imperativos de la habilidad, relativos a la solución de problemas técnicos contingentes, $y$, por otra, en imperativos de la prudencia, relativos a la contribución a la búsqueda de la felicidad, encomendada indefectiblemente al ser humano debido a su naturaleza empírica ${ }^{8}$. $\ll \mathrm{El}$ imperativo hipotético que representa la necesidad práctica de la acción como medio para la promoción de la felicidad es asertórico. No cabe presentarlo simplemente como necesario para un propósito incierto y meramente posible, sino para un propósito que puede presuponerse con seguridad y a priori en cualquier hombre, porque pertenece a su esencia. Ahora bien, la habilidad para elegir los medios relativos al mayor bienestar propio puede ser llamada prudencia en el sentido más estricto. Así pues, el imperativo que se refiere a la elección de los medios para la felicidad propia, o sea, la prescripción de la prudencia, sigue siendo siempre hipotético; la acción no es mandada sin más, sino sólo como medio para algún otro propósito» (IV, 415-416).

A nosotros solamente nos interesa el imperativo hipotético relacionado con nuestra felicidad en la vida. Se presentan aquí miles de problemas, de los cuales en lo que sigue sólo podemos referirnos a algunos.

Kant suaviza y templa ahora el carácter imperioso de ambos imperativos y los clasifica bajo los epígrafes de: «Reglas de la habilidad, o consejos de la prudencia» $(\mathrm{IV}, 416)^{9}$. Puesto que el ser humano, desde un punto de vista puramente empírico, no sabe «lo que realmente quiere» $(\mathrm{IV}, 418)$ y no puede desenvolver concepto determinado alguno de la condición de la felicidad de su vida entera, estos consejos o «sugerencias» (IV, 418) de la prudencia son sumamente vagos. En relación con el pasaje citado anteriormente, Kant

${ }^{7}$ Hume, A Treatise of Human Nature, Il 3, 3, 1896, p. 415: «Reason is, and ought only to be, the slave of the passions, and can never pretend to any other office than to serve and obey them».

${ }^{8}$ La dicotomía entre el deber condicionado y el incondicionado aparece ya en el escrito premiado de 1763 Investigación acerca de la nitidez de los principios de la teología natural y la moral, en el que, junto a la felicidad, se aduce la solución técnica de un problema matemático como finalidad de la acción (II, 298).

9 Cf. aquí el escrito premiado de 1763 , en el que la «necessitas problemática» no contiene obligación alguna, sino únicamente prescripciones e indicaciones (II, 298). 
introduce la siguiente nota: «El término "prudencia" admite una doble acepción según nos refiramos a la "prudencia mundana" o a la "prudencia privada". La primera es la habilidad que posee un hombre para tener influjo sobre los demás en pro de sus propósitos. La segunda es la pericia para hacer converger todos estos propósitos en pro del provecho duradero. Esta última es aquella a la que se retrotrae incluso el valor de la primera, y de quien se muestra prudente con arreglo a la primera acepción, más no con respecto a la segunda, sería más correcto decir: es diestro y astuto, pero, en suma, es imprudente» (IV, 416). Aquí se encuentra el meollo de la prudencia pragmática y el fundamento del imperativo de la prudencia: todas las intenciones que de hecho tenemos deben ponerse en relación, a modo de prueba, con la totalidad de nuestra vida. Kant retoma aquí una vieja recomendación de la praxis vital, la de preguntarse ante todas las acciones si éstas se acomodan al proyecto de la vida en su conjunto [cf. también la $K r V$, A 802: «La libertad práctica puede demostrarse por experiencia [...] Estas reflexiones acerca de lo deseable, esto es, bueno y provechoso, se basan en la razón. De ahí que ésta dicte también leyes que son imperativos, es decir, leyes objetivas de la libertad»]. El que convierte esta regla en criterio de las disposiciones de su voluntad y de sus acciones no seguirá los impulsos de placer o displacer tan sólo momentáneos sin preguntarse previamente si la acción que se pretende se ajusta al concepto de su vida en conjunto y de su aspiración a la felicidad. El que formula esta pregunta no hará, por ejemplo, aquello que perjudique a su salud física y psíquica. Kant critica el imperativo de la prudencia, no obstante, con el ya mentado argumento, que se encuentra con frecuencia en sus escritos. No es posible formar un concepto de lo que propiamente se quiere, $i$ es la riqueza un fin con sentido, o el matrimonio, o una vida larga y saludable? El concepto de la felicidad es de naturaleza indeterminada, puede transformarse como un camaleón: «De aquí se sigue que los imperativos de la prudencia, hablando con propiedad, no pueden mandar, es decir, que no pueden presentar objetivamente acciones como práctico-necesarias y han de ser tenidos más bien como recomendaciones (consilia) que como mandatos (praecepta) de la razón [...]» (IV, 418). La prudencia no sabe ella misma lo que al final resulta realmente prudente.

De este modo Kant modera manifiestamente el carácter coactivo de los imperativos de la prudencia; se aferra, no obstante, en la medida en que habla del imperativo hipotético, al deber (sollen) condicionado prácticamente y a la coacción de la voluntad. ¿Por qué debe el agente atenerse al medio $\mathrm{X}$ o $\mathrm{Y}$, que ha sido elegido prudentemente, cuando él quiere $\mathrm{Z}$ ? ¿No se pone de manifiesto en los dos casos del imperativo hipotético un estado de cosas? $\mathrm{El}$ que quiere, por ejemplo, $\mathrm{Z}$ tiene que hacer $\mathrm{X}$ e $\mathrm{Y}$; éste es un problema puramente epistémico. El imperativo hipotético se dirige a una persona que quiere algo, que conforme a una determinada máxima o regla avista un propósito. Este propósito se puede realizar solamente a través de una o varias 
acciones (facultativas o consecutivas) qua medios necesarios de forma indispensable. El querer del propósito remite analíticamente al o a los medios de su realización, sin ser, no obstante, idéntico con él o con ellos, ni con respecto a la cosa ni con respecto al saber. Es posible, sin embargo, concebir una conciencia que no acierta a pasar del deseo al querer, sino que avista numerosos propósitos, que cree querer, pero que desea sólo facultativamente. A esta conciencia lábil se le contrapone el imperativo hipotético qua enunciado práctico como principio de la realidad y como coacción a la consecuencia: si tú realmente quieres conseguir $\mathrm{Z}$, entonces haz $\mathrm{H}$ como el medio indispensable que se encuentra en tu poder para realizar $Z$. Los imperativos hipotéticos nos obligan «exclusivamente a que, en vista de nuestro conocimiento acerca de los medios, nos decidamos o bien por estos medios o bien en contra del fin», así resume Bern Ludwig la idea esencial ${ }^{10}$. Se conmina al agente a atenerse a la consecuencia de la intención de su voluntad y a realizar $\mathrm{H}$ como medio para $\mathrm{Z}$. La intención de la voluntad misma se encuentra, por supuesto, al igual que los medios que analíticamente se ponen a la par, bajo el derecho de veto de la moral. Si $\mathrm{Z}$ o $\mathrm{H}$ se frustran ante el control moral del imperativo categórico, la prudencia se viene abajo. Se querrá computar como prudencia y como juicio el que en la realización de $\mathrm{H}$, dado el caso, la prudencia ajuste $\mathrm{H}$ y $\mathrm{Z}$ y las relacione la una con la otra en un proceso de aprendizaje empírico, de manera que no se siga $\mathrm{H}$ a ciegas por mor de la consistencia. Kant formula, sin embargo, el imperativo hipotético no desde la perspectiva del agente procesual, sino desde la del cognoscente imparcial, para el que no se da ninguna conexión reactiva de $\mathrm{H}$ y Z en el transcurso de la acción; pensemos en el «more geométrico» en caso de la solución de los problemas de Euclides.

Se aspira a la vaga felicidad en el horizonte de nuestra vida. Si bien la representación misma de la felicidad, es decir, la finalidad de la acción, se escruta desde el punto de vista de su prudencia - $i$ es prudente querer $Z$ ? $i S i$ mediante la acción $\mathrm{H}$ consigo la finalidad $\mathrm{Z}$, seré verdaderamente feliz?-. $\mathrm{Z}$ se muestra al punto de nuevo como medio para la consecución de la felicidad, que se aplaza una y otra vez. Puede, por ejemplo, ser imprudente situar la felicidad en la adquisición de riquezas o placer sensual, pero prudente, sin embargo, dedicarse a la obtención de honores o la adquisición de conocimientos y luego reflexionar acerca de los medios y los caminos a través de los cuales puede lograrse el propósito determinado al que se aspiró una vez. Si nos atenemos al carácter siempre hipotético de los consejos pragmáticos, debe considerarse ya la elección de un camino vital, es decir, la determina-

10 Ludwig, 1999, p. 121. Enlazando con Ludwig expone Steigleder: «puesto que un ser finito capaz de actuar no quiere acometer una acción simple y llanamente, porque de no ser así se comportaría de forma inconsecuente, se desarrolla para dicho ser a partir de la interconexión lógica la exigencia de comportarse de modo consecuente» (Steigleder, 2002, p. 45; cf. allí la bibliografía pertinente). 
ción y fijación de la felicidad, por ejemplo, en la riqueza, a su vez como un medio para llegar a conseguir la felicidad. Esto último se adapta bien a la idea general de que no existe para nosotros la felicidad en una forma determinada; tal vez por ello Kant en la Crítica de la razón pura hablaba, como hemos visto, de un «concepto usurpado», que no es posible deducir ( $K r V$, A 84). La obcecada prudencia: aunque resulte utópico obtener una felicidad determinada, la prudencia aplica todos los esfuerzos imaginables para idear y realizar la obtención de lo que no se puede lograr. El ser humano carga sobre sí este empeño ilusorio no por prudencia, sino por fuerza, puesto que para el ser humano, es decir, para un ser racional afectado por la sensibilidad, no existe ninguna otra alternativa. El carácter coercitivo de nuestra aspiración general a la felicidad conduce a que ésta en su forma general no pueda estar sometida a veto alguno por parte de la moral - de ahí la necesidad de la realidad práctica del bien supremo, en el que se unen la moralidad y la felicidad en proporción a ella (el tema de la dialéctica de la Crítica de la razón práctica, $K p V, 1788)$ - . En el punto 2 se amplían las explicaciones al respecto.

En la lección de antropología publicada, la acción pragmática se relaciona con el trato con los seres humanos, no con las cosas, es decir, con el «prattein», no con el «poiein», en terminología aristotélica. Se trata siempre de una psicología orientada a la praxis. Acabamos de ver que el imperativo pragmático de la prudencia se delimita con respecto al imperativo técnico en razón de que el primero tematiza el verdadero propósito de todo ser humano, mientras que el segundo se ocupa de problemas técnicos, relativos a cosas, que se nos presentan únicamente como posibles. La realización de la felicidad puede naturalmente constituir en parte también un problema técnico, relacionado con cosas, de modo que los imperativos de la prudencia coloquen a los imperativos de la habilidad a su servicio.

En la Crítica de la razón práctica ya no se habla de imperativos hipotéticos de la prudencia, cuyo «tú debes» presupone libertad, sino que se habla más modestamente de «Máxima del amor hacia uno mismo» (prudencia) $(\mathrm{V}, 36)^{*}$, a partir de lo cual la Crítica del discernimiento extrae la consecuencia de despojar explícitamente a los imperativos hipotéticos de su mandato imperativo y dejarlos a cargo de la filosofía teorética: «Todas las reglas técnico-prácticas (esto es, las del arte y la destreza en general, o también de la prudencia como destreza para influir sobre los seres humanos y en su voluntad) sólo tienen que contabilizarse como corolarios de la filosofía teórica, pues sólo atañen a la posibilidad de las cosas según conceptos de la naturaleza, a lo cual no pertenecen únicamente los medios que se encuentran al respecto en la naturaleza, sino también la voluntad misma (como capacidad desiderativa y, por ende, como capacidad de la naturaleza), en tanto que

\footnotetext{
* En castellano se cita siguiendo la traducción de Roberto $\mathrm{R}$. Aramayo, Crítica de la razón práctica, Madrid, Alianza Editorial, 2000 (N. T.).
} 
pueda verse determinada a esas reglas por móviles de la naturaleza» $(\mathrm{V}, 172)^{*}$. En caso de que el ser humano no sea más que un bípedo prudente, estará más cerca del zorro y del pueblo de demonios que de un ser racional puro afectado por la sensibilidad. ¿Ha modificado Kant aquí su concepción con respecto a la de la Crítica de la razón pura que se adujo arriba?

\section{Moral y prudencia en conflicto}

En el campo de la moral pura es la prudencia en la filosofía crítica la antípoda de la determinación de la voluntad mediante el imperativo categórico y con ello de la moralidad. La «ley fundamental de la razón pura práctica» dice: «Obra de tal modo que la máxima de tu voluntad siempre pueda valer al mismo tiempo como principio de una legislación universal» (V, 30). Pues bien, irrevocablemente tiene validez que: «Ser feliz constituye necesariamente el anhelo de todo ente racional que, sin embargo, sea finito y, por lo tanto, representa un ineludible fundamento para determinar su capacidad desiderativa» (V, 25; cf. también 35). El realizar nuestra representación de la felicidad, que es una función de las inclinaciones, es una tarea que corresponde a la prudencia; ésta queda como está, de ahí el «al mismo tiempo» (zugleich) en la formulación del imperativo categórico que hemos aducido ${ }^{11}$; «al mismo tiempo», es decir, conservando la finalidad pragmática, hemos de someter la máxima de nuestra acción a la prueba de si se adecua a la ley, para acto seguido tomar nota con todo rigor del resultado de la prueba. El imperativo categórico excluye exactamente en este punto cualquier consideración propia de la prudencia, colocando así a la prudencia que se atreve a la decisión de la acción en una posición contraria a la moral. La prudencia, que quiere determinar a la voluntad a partir de sí misma, tiene que ponerse en relación con un contenido como fin, conocido previamente, que evoca la inclinación, así como con las acciones necesarias para su consecución. La determinación moral de la voluntad kantiana, por el contrario, emancipa a la voluntad pura con respecto a todos los conocimientos y contenidos teoréticos y deja la decisión acerca de si la acción efectivamente se realiza o no en manos del principio de autonomía, de la legalidad, sin deferencia alguna hacia el contenido externo a la voluntad. Todas las determinaciones de la voluntad mediante contenidos, incluso el bien platónico, son heterónomas y además eudemonistas, porque únicamente el sentimiento de placer y displacer puede mediar entre el contenido ideado y la voluntad.

* En castellano se cita siguiendo la traducción de Roberto R. Aramayo y Salvador Mas, Crítica del discernimiento, Madrid, Antonio Machado, 2003 (N. T.).

"Cf. la formulación en la GMS: «Así pues, el imperativo categórico es único y, sin duda, es éste: obra sólo según aquella máxima por la cual puedas querer que al mismo tiempo se convierta en una ley universal» (IV, 421, 6-8; también, 429, 10, y 434, 13). 
Aquí, en nuestra disposición natural, rige siempre el esquema: contenidosentimiento de placer y displacer-voluntad (al contenido cognitivo le sigue la reacción emocional y a continuación la determinación volitiva).

«Incluso el Bien platónico». Pero ¿no es Kant en la filosofía moral, dejando por un momento de lado el sistema de las virtudes, un platónico? Con el fin de aclarar esta cuestión, importante en relación con la prudencia, debe elucidarse brevemente la cambiante relación de Kant con Platón en cuestiones de filosofía práctica.

En la disertación de 1770 De mundi sensibilis atque intelligibilis forma et principiis, Kant escribe en el § 9: «Así pues, la filosofía moral, en cuanto que suministra los primeros principios del juicio [moral], no es conocida sino por el intelecto puro y pertenece a la filosofía pura; por esto, Epicuro, que reduce sus criterios al sentido del placer o del hastío, es con suma razón censurado, juntamente con algunos neotéricos, que en cierta medida le siguen de lejos, como Shaftesbury y sus secuaces. En todo género de cosas cuya cantidad es variable, lo máximo de perfección se llama ahora Ideal, en Platón, Idea (cual es su idea del Estado) [...]» ${ }^{12}$. Para el enjuiciamiento de la cualidad moral de una acción humana, o, por ejemplo, de un estado, disponemos de un patrón ideal, accesible a la filosofía pura y a su idea de Dios, como la del «maximum perfectionis»: reconocemos ese maximum ideal teoréticamente y lo utilizamos como criterio para el enjuiciamiento de las acciones e instituciones. Enemigos de ese «platonismo» son, tal como se cita, «Shaftesbury y sus secuaces», empiristas, y, como epicúreos, hedonistas, entre los cuales cabría contar a Kant de acuerdo con determinadas expresiones previas a este giro de 1770 , cuando en la «doctrina de la virtud» quería investigar la naturaleza humana para desarrollar luego, a partir de estos conocimientos, las prescripciones morales adecuadas (cf., en particular, II, 311). Por aquel entonces, es decir, en 1765, la moral era una sección de la doctrina de la prudencia en el sentido del empirismo inglés; en 1770 se sigue un apriorismo platónico en rotundo rechazo contra el empirismo y contra su fundamentación de las normas en la naturaleza fáctica. Pero este apriorismo moral está vinculado a la división del mundo en un «mundus sensibilis» y en un «mundus intelligibilis», o, lo que es lo mismo, en «phanomena» y «noumena». En principio se supondrá también aquí una pieza heredada de la filosofía platónica, pero es éste un error que se pone al descubierto fácilmente, porque para Platón no puede haber ninguna ciencia exacta de los fenómenos como meras representaciones; Kant, sin embargo, quiere precisamente hacer posible el conocimiento científico de fenómenos en el espacio y el tiempo. De este modo se puede afirmar que Kant se convierte

${ }_{12}$ Kant, De mundi sensibilis atque intelligibilis forma et principiis, $\$ 9,1958$, pp. 29-31. [En castellano se cita siguiendo la edición bilingüe de José Gómez Caffarena, Immanuel Kant. Principios formales del mundo sensible y del inteligible (Disertación de 1770), Madrid, Consejo Superior de Investigaciones Científicas, 1996, (N. T.)]. 
en platónico en 1770 solamente en la filosofía moral; la prudencia, por el contrario, en tanto que incompetente desde el punto de vista moral por ser relativa a contenidos empíricos (¡no a contenidos en general!), es declarada extraterritorial. Sólo el imperativo pragmático se arrastra todavía en la doctrina general de los imperativos prácticos a modo de contraste.

Vemos que Kant reclama a Platón para la filosofía moral, pero no para la doctrina de los dos mundos, y ya sabemos que Kant en 1770 no puede disponer todavía del principio de la autonomía y del formalismo, que será la base de la filosofía moral crítica, en la que Platón perderá su función de guía.

El platonismo en el sentido de la filosofía moral cede su puesto a un antiplatonismo, como muy tarde en la Crítica de la razón práctica, en la relación entre el conocimiento y la voluntad. Mientras que Kant en 1770, ingenuamente en cierta medida, adopta la idea o el ideal platónico como orientación para el juicio moral, llega en 1788 a la conclusión de que Platón no se distingue en principio de Epicuro y sus adeptos. La determinación «antiplatonismo» es más precisa cuando se la relaciona solamente con la doctrina de las ideas en un sentido epistémico; si se toma la voluntad pura por sí misma es posible hablar, siguiendo esta pauta, de un platonismo de la voluntad, dado que la razón pura práctica comparte con la idea platónica la separación y la pureza con respecto a toda sensibilidad. En la dilucidación de la Crítica de la razón práctica se expresa la posición antiplatónica en la medida en que la ley moral, o el imperativo categórico, se coloca en la cúspide como indeducible, o sea, en el lugar que en la filosofía teórica de la Crítica de la razón pura ocupa la intuición pura, que no puede deducirse de concepto alguno (Kant mismo lo ve así; cf. Refl. 7201, XV, 275).

Con respecto a la prudencia, Kant se mantiene siempre firme, si bien en otras constelaciones, en la posición de 1770, que era ya la de 1763: la prudencia es de naturaleza instrumental y no puede proporcionar fundamento alguno a la moral. En la Fundamentación para una metafísica de las costumbres se dice, de conformidad con la fórmula de la autonomía del juicio y la acción moral: «Qué he de hacer, por lo tanto, para que mi querer sea moralmente bueno; para eso no necesito una penetrante agudeza que sepa calar muy hondo. Sin experiencia con respecto al curso del mundo, incapaz de abarcar todos los acontecimientos que se concitan en él, basta con que me pregunte: "¿Puedes querer también que tu máxima se convierta en una ley universal?"», (IV, 403). El procedimiento prudente, sugerido por nuestra naturaleza sensible, dice, por el contrario, que debo adquirir conocimientos antes de actuar, de modo que la elección prudente de los fines de la acción es guiada por mis inclinaciones. Se llega así a la «paradoja del método» sacada a la luz por Kant, «que el concepto de lo bueno y lo malo no habría de quedar determinado antes de la ley moral (aun cuando, conforme a las apariencias, tendría que haber sido colocado incluso como fundamento de la mis$\mathrm{ma}$ ), sino que tal concepto (como también sucede aquí) sólo habría de verse 
determinado tras contar con esa ley e igualmente ser determinado por la ley misma» (V, 62-63). La sucesión natural invierte sus términos, puesto que ahora la voluntad no se determina a través de un contenido antepuesto del deseo o de la aversión, sino que, a la inversa, el principio formal de la determinación de la voluntad convierte en primera instancia contenidos cualesquiera en buenos o malos. En el primer caso, predomina la prudencia de la razón instrumental, en el segundo, la moralidad de la razón para práctica; en el primero, tiene la palabra la serpiente, en el segundo, el Dios en nosotros ${ }^{13}$.

¿Cómo es posible el imperativo categórico, indiferente a la prudencia y que, en caso de conflicto, aplasta toda prudencia? En la Fundamentación para una metafísica de las costumbres y en los primeros parágrafos de la Crítica de la razón práctica, Kant lleva a cabo en primer lugar la «pars destruens» de su explicación: una voluntad que depende de inclinaciones $\mathrm{y}$, por tanto, de contenidos hacia los que se orientan estas inclinaciones no puede bastar para un principio pensable del deber $(G M S)$ o para un principio de la razón pura práctica. El primer paso positivo es ahora la obtención de una alternativa concebible, que pudiera hacer justicia a la exigencia del deber y de la razón. El contenido objetivo o la materia del querer tendría que ser sustituido por la forma pura de una ley, y la inclinación subjetiva hacia ese contenido material por el respeto hacia la ley. Así, el deber o la determinación de la voluntad a partir de la razón pura significaría: «que una acción es necesaria por respeto a la ley» (IV, 400). Este principio se puede explicitar más de cerca como imperativo categórico: «Obra sólo según aquella máxima por la cual puedas querer que al mismo tiempo se convierta en una ley universal» (IV, 421). Este imperativo, sin embargo, debe evidenciarse no únicamente como el único principio posible de la moralidad, pero que puede ser pensado sólo problemáticamente, sino como objetivamente real para mi voluntad y para la voluntad de todo ser racional afectado por la sensibilidad. Aquí se escinden los caminos de la $G M S$ y de la $K p V$.

La GMS argumenta en el tercer parágrafo como demostración de la realidad práctica objetiva del imperativo, aproximadamente de la siguiente manera: 1) Mediante la mera determinación conceptual se puede establecer que una voluntad libre y una voluntad bajo la ley moral son lo mismo. 2) Ahora un sujeto racional se ve a sí mismo como libre y atribuye justamente a todos los seres racionales esta idea de la libertad, que a su vez conduce a la determinación legal de la libertad. Queda sin aclaración, no obstante, cómo este sujeto debe estar sometido a la ley, debiendo concederle la primacía incondicional ante cualesquiera otras estimaciones de valor. 3) La respuesta a ambas preguntas se da mediante un doble punto de vista acerca del mundo: como seres racionales libres, autónomos y, por lo tanto, legisladores, pertenecemos al mundo inteligible; como seres que están sometidos a la ley del mundo

${ }^{13}$ Cf. el «Deus est in nobis», VII, 48, y XXII, 130. 
inteligible, pertenecemos, sin embargo, al sensible. Toda vez que el primero, en tanto que fundamenta qua cosa en sí al mundo sensible, ostenta un rango superior, lo estimamos más que al mundo sensible de las apariencias; su ley concierne al ser racional como cosa en sí, que tiene validez incondicional frente a la apariencia sensible. De esta manera, el doble concepto crítico del mundo resuelve un problema que la conciencia subjetiva de la libertad no era capaz de solucionar. Esta deducción adolece de falta de claridad: la libertad de la conciencia subjetiva tiene que ser el sostén de toda praxis, es decir, también de la mera prudencia y habilidad. Kant despierta esta impresión con formulaciones como: «Mas resulta imposible imaginar una razón que con respecto a sus juicios [!] reciba un encauzamiento diferente al de la propia conciencia, pues entonces el sujeto no adjudicaría la determinación del discernimiento a su razón, sino a un impulso» (IV, 447-448) ${ }^{14}$. Esta libertad presente en la autoconciencia y que, por lo tanto, ha de presuponerse no necesita estar limitada a la libertad moral; para confirmación de este supuesto, Kant añade más adelante que el entendimiento, ¡no la razón pura práctica!, «también es autoactividad (Selbstthätigkeit)» (IV, 452). Es decir, nos encontramos en la Crítica de la razón pura ante el problema de que, por una parte, la libertad está garantizada a través de la autoconciencia de un sujeto racional en todas sus acciones y, por otra parte, libertad y ley moral son conceptos intercambiables, es decir, que está excluida la libertad en el caso de acciones de la mera prudencia.

En la $K p V$ Kant toma otro camino, tras el rechazo de la determinación moral de la voluntad a través del contenido y la inclinación (\$§ 1-6) se formula el único principio posible de la libertad y se instaura con pretensión de poder como ley suprema de facto; el imperativo categórico es un Faktum de la conciencia, indemostrable e incontestable. Él mismo determina lo que es bueno y malo, él mismo crea, con el sentimiento de respeto, el motivo y el interés de la observancia. Se confirma aquí que la prudencia, con un modo de vida vinculado a las inclinaciones, no tiene acceso a las decisiones en torno a la acción, sólo se echa mano de ella a condición de que la razón pura práctica no interponga un veto.

La contraposición de moral y prudencia no solamente es relevante para el control personal de la acción, sino también para la acción estatal, lo que se expresa de una manera particularmente drástica en su escrito Hacia la paz perpetua $(1795)^{*}$. En el apartado «Sobre la discrepancia entre la moral y la

${ }_{14}$ Cf. Heinrich, 1975, 65 ff. Según Heinrich, la libertad en la autoconciencia del juicio no es inmune frente a la objeción de fatalismo; la libertad moral alcanza esta inmunidad en primera instancia a través de la deducción. Acerca de la discusión contemporánea de la restricción de la libertad a la razón pura práctica y su legislación, cf. en BITTNER y CRAMER (eds.), 1975, pp. 241-301, las contribuciones de Carl Christian Erhard Schmid, Carl Leonard Reinhold, Leonhard Creuzer y Johann Gottlieb Fichte.

* En castellano se cita siguiendo la traducción de Joaquín Abellán, Sobre la paz perpetua, Madrid, Alianza Editorial, 2002 (N. T.). 
política respecto a la paz perpetua» (VIII, 370), se recurre ya al principio a la figura de la inversión, que nosotros conocemos de la «paradoja del método»: la política es o bien la ejecución del derecho conforme a la moral o bien «una teoría general de la prudencia, es decir, una teoría (!) de las máximas [...] para elegir los medios adecuados a sus propósitos interesados, es decir, esto equivaldría a negar que exista una moral como tal» (VIII, 370). A continuación aparecen las serpientes: «La política dice: "sed astutos como la serpiente"; la moral añade (como condición limitativa): "y cándidos como las palomas"» (VIII, 370). Esta antitética determina la distinción del político moral y el moralista político: «Ahora bien, yo puedo concebir un politico moral, es decir, un político que entiende los principios de la habilidad política de modo que puedan coexistir con la moral, pero no un moralista políti$c o$, que se forje una moral útil a las conveniencias del hombre de Estado» (VIII, 372) ${ }^{15}$.

Una esperanza de que no todo degenere en la barbarie de la razón de estado y el maquiavelismo se alberga en el concepto de derecho: «De todos estos circunloquios de una teoría inmoral de la prudencia para el establecimiento del estado de paz entre los hombres, partiendo del estado natural de guerra, se desprende, al menos, lo siguiente: que los hombres no pueden prescindir del concepto de derecho ni en sus relaciones privadas ni en las públicas y no se atreven abiertamente a basar la política en medidas de habilidad, negando obediencia al concepto de un derecho público [...]» (VIII, 375-376).

Con esto se han esbozado algunos elementos de la oposición, necesaria desde un punto de vista sistemático, entre prudencia y moral, como contrapunto sigue ahora la esfera de la simbiosis entre ambas.

\section{La compatibilidad de la prudencia y la moral}

La moral racional kantiana no apunta ni a un yermo de las inclinaciones, para alcanzar el cementerio de la apatía estoica, ni tampoco quiere llevar toda prudencia a la ruina. Existen, por el contrario, diversas formas de simbiosis entre la moral y la prudencia, de las que aquí sólo se pueden mencionar algunas. De pronto aparece la prudencia y el discernimiento como objeto de un deber. La prudencia tiene únicamente una función subsidiaria y no puede disponerse contra la objeción de la moral, pero ella puede y debe desarrollarse bajo la dirección de la moral. Mientras que los deberes estrictos o perfectos en la GMS se ejemplifican mediante la prohibición del suicidio y de la mentira, el favorecer la propia cultura y la contribución a la felicidad ajena se toman como deberes imperfectos: «Un tercero encuentra dentro de sí un talento que con cierto cultivo podría convertirlo en un hom-

${ }^{15}$ Kant toma la figura de la oposición de la teología moral y moral teológica de la $K r V$, A 632. Con respecto a este asunto ya Platón, Eutyphron, $10 .^{\mathrm{a}}$ 
bre útil para diversos propósitos [...] Pues como ser racional quiere necesariamente que se desarrollen en él todas las capacidades, ya que le son dadas y resultan útiles para toda suerte de posibles propósitos» (IV, 422-423). «El cultivo (cultura) de las propias facultades naturales (las facultades del espíritu, del alma y del cuerpo), como medio para toda suerte de posibles fines, es un deber del hombre hacia sí mismo», se dice en los Principios metafísicos de la doctrina de la virtud (VI, 444). Este deber imperfecto o amplio, no siendo un fin moral en sí mismo, es, no obstante, un mandato, cuyo cumplimiento hace que me sea posible no claudicar en la observancia de los deberes estrictamente morales. La prudencia y la agudeza se encuentran entre estas fuerzas anímicas imprescindibles para el ser humano.

El imperativo categórico del deber imperfecto o amplio de procurar el desarrollo de las propias fuerzas anímicas y con ello a la vez la prudencia no debe confundirse con el ámbito del imperativo hipotético de la prudencia. Pero ¿es posible cultivar, en general, la prudencia? Argúyase un reparo procedente de un escrito de Kant: «La falta de esta capacidad es, de hecho, lo que llamamos necedad y tal defecto no tiene remedio. Una cabeza obtusa o limitada, a la que no falta sino el correspondiente grado de entendimiento y los conceptos propios de éste, puede muy bien llegar, a base de estudio, hasta la misma erudición. Pero, teniendo en cuenta que también en tales casos suele faltar el discernimiento (secunda Petri), no es raro encontrar hombres muy cultos que, al hacer uso de su especialidad científica, dejan traslucir ese incorregible defecto» ${ }^{16}(\mathrm{KrV}$, A 134). Kant constata serenamente que la falta es innata y no se puede subsanar. Nosotros hemos pensado con un poco más de optimismo, no en la imposibilidad de erradicar la estupidez, sino en la posibilidad de cultivar la prudencia, a lo que se consagra también la antropología pragmática; también el discernimiento (Urteilskraft) puede verse «aguzado» (KrV, A 134). Si la falta de discernimiento es propiamente la estupidez, y la estupidez es propiamente la falta de prudencia, entonces el discernimiento y la prudencia tendrían que tender a ser idénticos. Dado que la doctrina del discernimiento (entre el entendimiento y la razón) es, sin embargo, un campo teórico nuevo y complejo, nos damos por satisfechos con esta referencia.

Otro punto concierne a la convergencia temporal de prudencia y moralidad, de utilidad y buena intención. Se actúa prudentemente a la longue, cuando se actúa moralmente. Este principio tiene validez tanto en la esfera del derecho público como en la de la moralidad privada. El puente entre ambas tiene una larga tradición, llamo la atención aquí únicamente sobre $D e$ officiis de Cicerón y sobre el Contrato social de Rousseau. Cicerón muestra la conexión interna de «honestum» y «utile»: nada es verdaderamente

${ }^{15}$ La expresión «secunda Petri» remite a la ordenación de la Lógica de Petrus Ramus (15151572), en la que la doctrina del juicio aparece en la segunda posición, después de la doctrina del concepto. 
honesto sin utilidad, nada es útil sin honestidad. Y, como contrapartida: «quod turpe sit, id numquam esse utile» ${ }^{17}$; Rousseau declara al principio de su obra: «Je tâcherai d'allier toujours dans cette recherche ce que le droit permet avec ce que l'intérêt prescrit, afin que la justice et l'utilité ne se trouvent point divisées» ${ }^{18}$. Kant conoce a la perfección ambos escritos; éstos demuestran la necesidad de la unión de la moralidad y la prudencia para que no haga su aparición la separación entre la ética de principios y el utilitarismo ¿Cómo se puede mostrar entonces que la moral finalmente conduce a lo útil, que la honradez es la mejor política y que el idealista moral es el auténtico realista?

En la esfera individual, la doctrina de los postulados de la Crítica de la razón práctica debe poner de manifiesto que el sumo bien práctico, con la unión de la moral y la correspondiente felicidad, no es una quimera vacía, sino que posee realidad práctica objetiva. Mientras que la componente moral se encuentra por completo en nuestro poder, no ocurre lo mismo con el éxito de la acción ordenada por la moral para la realización de buenos propósitos; aquí se añade a la moral la creencia en un poder supraterrenal, que unifica la moralidad de la acción con su buen resultado tanto en éste como en el otro mundo. Éste es el problema: «Porque precisar de la felicidad, ser digno de ella y, sin embargo, no participar en la misma es algo que no puede compadecerse con el perfecto querer de un ente racional que fuera omnipotente, cuando imaginamos un ser semejante a título de prueba» (V, 110). Mediante complicados procesos de pensamiento Kant intenta mostrar que este bien supremo: la unificación de la moralidad y la felicidad proporcional a ella, posee realidad práctica objetiva y que no necesitamos dudar del sentido de nuestra acción por deber; ser moral no puede a la larga atentar contra la prudencia y su aspiración a la felicidad. En la esfera política, Kant opera análogamente en relación con la Providencia, que con mano invisible conduce a la armonía entre la legislación de la naturaleza y la legislación de la libertad; que la historia se encamina, o, dicho con mayor precaución, tiende, hacia aquello que demanda la razón pura práctica. Se produce aquí también la convergencia entre «honestum» y «utile» de tal manera que el agente moral tanto en su vida privada como pública puede, no por azar sino conforme a un principio de la razón, esperar que realmente se realice el propósito de su acción. La filosofía de la historia debe mostrar que no es imposible ver la historia en su totalidad bajo la guía de la Providencia. Existe, así, una oportunidad razonablemente fundamentada de no dudar, sino de ver reconciliadas a largo plazo la acción moral y el buen resultado, la moral y la utilidad, la razón pura práctica y la prudencia: «Por lo demás, debe y puede ser la especie humana misma la creadora de su dicha; únicamente, que lo será, no puede inferirse a priori de las disposiciones naturales por nosotros

${ }^{17}$ Cicerón (o. J.), 114, De officiis, III, 12, 49.

${ }_{18}$ Rousseau, Du contrat social (Préface), III, 351, 1959 y ss. 
conocidas en ella, sino sólo de la experiencia y la historia, con una expectativa tan ampliamente fundada como es necesario para no dudar de este su progresar hacia lo mejor, sino para fomentar con toda prudencia e iluminación moral el acercamiento a este fin (cada cual cuanto le sea dado)» (VII, 328-329).

\section{Prudencia y libertad}

Tras estas aclaraciones en relación con el contraste y la compatibilidad entre la prudencia y la moral debe investigarse una vez más con mayor precisión el ámbito de los imperativos hipotéticos, tal como Kant los expone particularmente en la GMS.

La libertad se relaciona siempre con la acción regulada, orientada a fines. La regla de una acción se denomina máxima. Las acciones son medios para la consecución de fines. El ser humano, conforme al imperativo categórico, puede y debe ejercer un control moral tanto de los medios como de los fines que se pretenden. Conforme al imperativo técnico y pragmático puede y debe controlar los medios en relación con su utilidad para el fin que se presupone en la hipótesis. En el caso de la prudencia y, por tanto, de los imperativos hipotéticos pragmáticos, el fin es la felicidad. Podemos hablar de un control técnico también en el caso de los imperativos hipotéticos de la prudencia, porque de lo que se trata de todos modos en el caso del imperativo hipotético es de juzgar la adecuación de los medios en relación con el fin que se presupone. En la Metafísica de las costumbres Kant habla de: «fines, que el hombre se propone atendiendo a los impulsos sensibles de su naturaleza» y añade que se trataría entonces de prescripciones de fines de tipo técnico o pragmático, para las que: «la regla de la prudencia en la elección de sus fines» sería decisiva (VI, 385) - la explicación del imperativo categórico prosigue aquí, incluyendo también el fin en el control prudencial-. Esto suena prima facie convincente, puesto que la prudencia para la vida parece demandar un análisis crítico también de nuestros propósitos de acción singulares.

El control moral tanto de los medios como de los fines de la acción se enuncia en el imperativo categórico. El control moral de los medios se lleva a cabo con completa exclusión de cualquier consideración de la finalidad de la acción, por tanto, también de los fines imperfectos, objeto de mandato moral. De este modo se excluye una colisión de los mandatos y las prohibiciones, lo que es sumamente importante. El control técnico se refiere al aspecto cognoscible teoréticamente de los medios previstos para una acción planeada. Puede tratarse de fenómenos del sentido interno o del sentido externo, de objetos matemáticos, de operaciones lógicas (que Kant no menciona) o también de experimentos de las ciencias naturales: «Todas las ciencias contienen alguna parte práctica, la cual consta de problemas relativos a 
un fin posible para nosotros y de imperativos sobre cómo puede ser alcanzado dicho fin», y, en relación con los imperativos pragmáticos: «El imperativo hipotético que representa la necesidad práctica de la acción como medio para la promoción de la felicidad es asertórico» (IV, 415).

Mientras que la exclusión moral de un medio para la realización de un determinado fin toma en consideración dicho medio enteramente de por sí, recubriendo el fin con un velo de ignorancia, el control técnico se tiene que conformar naturalmente con tomar en consideración el medio con relación a su adecuación para la realización del fin de la acción.

Es suficiente, a modo una vez más de resumen, lo dicho acerca de la estructura general de los imperativos categóricos e hipotéticos. Se presupone, obviamente, que el imperativo se dirige a una persona que posee la libertad de acatarlo o recusarlo, mientras que, notoriamente, uno no se dirige a las piedras con imperativos. La persona aludida, sea ella misma o no la promotora de la regla o de la ley, tiene que ser libre, tal como se imaginaba Kant la situación aproximadamente en el invierno de 1772-1773: «El Yo es el fundamento del entendimiento y de la facultad de la razón y del conjunto de las facultades superiores, puesto que todas estas facultades tienen su fundamento en que yo me observo y contemplo a mí mismo y lo que en mí ocurre. [...] En la partícula yo se encuentra incluso el concepto de la libertad, la conciencia de la espontaneidad [...] La personalidad hace que algo pueda serme imputado, y la personalidad surge del pensamiento Yo» (XXV, 10-11). En lo sucesivo debe ponerse de manifiesto que Kant se retracta paulatinamente de esta posición, sustrayendo con ello la mera prudencia del terreno de la libertad. Al mismo tiempo, sin embargo, en las explicaciones que no se ocupan explícitamente del problema de la libertad, se conserva el discurso habitual acerca de acciones libres también en las esferas técnica y pragmática. También la Antropología en sentido pragmático (1798) sitúa la diferencia decisiva entre la persona moral y la cosa en la conciencia del yo: «El hecho de que el hombre pueda tener una representación de su yo le realza infinitamente por encima de todos los demás seres que viven sobre la tierra. Gracias a ello el hombre es una persona, y por virtud de la unidad de la conciencia en medio de todos los cambios que pueden afectarle es una y la misma persona, esto es, un ser totalmente distinto, por su rango y dignidad, de las cosas, como son los animales irracionales, con los que se puede hacer y deshacer a capricho» (VII, 127). Esto puede haber sido concebido para el uso pragmático, la teoría kantiana, sin embargo, hace ya tiempo que se ha apartado de esta posición. La mera conciencia del yo pueden poseerla también seres racionales sin moralidad alguna y, por lo tanto, sin libertad, y el contenido de «debe» (Soll-Gehalt) de los imperativos hipotéticos se adjudica ahora a la naturaleza, ya no a la libertad.

Después de 1772-1773 y hasta la redacción de la Crítica de la razón pura, la problemática de la libertad se transfiere de la psicología a la cosmo- 
logía, ostentando allí en principio la libertad bajo la ley de la moralidad en el «mundus intelligibilis» el monopolio de la libertad en general. Esto tiene necesariamente como consecuencia que la doctrina de la prudencia sea expulsada de la doctrina de la libertad, del mismo modo que, en un movimiento análogo, el conocimiento propio del entendimiento. El «yo» que se reclama para este conocimiento ya no tiene absolutamente nada que ver con la libertad.

Nuestra cita de la temprana lección de antropología, documenta que Kant, en torno a 1772-1773, admite la conciencia del yo como fundamento del conocimiento de mí mismo como un ser libre. Todavía en 1775-1776 se dice en los apuntes de antropología «Friedlander» o, lo que es lo mismo, en Ms 400: «Este concepto del yo es enormemente fructífero, es la fuente de la que se deducen otras muchas cosas. 1) La substancialidad. El alma es el yo propiamente dicho, es un sujeto que no es predicado de ningún otro. 2) La simplicidad: puesto que es una unidad en sentido estricto, no tiene ningún pluralis [...]. 3) La espontaneidad que también se sigue de ahí, puesto que, cuando yo digo: yo hago, no soy movido» $(\mathrm{XXV}, 473)$.

En la $\mathrm{KrV}$, sin embargo, se impugna esta posibilidad de obtener a partir del puro «Yo pienso» el conocimiento de la sustancialidad y la inmaterialidad, o también de la libertad; acerca de ello trata el capítulo, que fue redactado relativamente tarde, sobre los "paralogismos de la razón pura» en la «dialéctica trascendental». Pero las citas aducidas anteriormente muestran que Kant también habla de libertad en contextos pragmáticos, que no apelan a la moral como único dominio de la libertad. Todavía en 1783 Kant argumenta contra el determinista Johann Heinrich Schulz y su Versuch einer Anleitung der Sittenlehre für alle Menschen ohne Unterschied der Religion (1783), de manera que la afirmación «no hay libertad» presupone la libertad. En primer lugar se mantiene, desde una perspectiva general, que «el fatalismo general, que en esta obra constituye el principio supremo, violento, que afecta a toda moral, puesto que convierte toda obra y omisión humanas en un mero juego de títeres, anula totalmente el concepto de obligación; que, por el contrario, el deber o el imperativo, que distingue la ley práctica de la ley natural, nos colocaría también en la idea totalmente fuera de la cadena natural, puesto que es absurdo e imposible sin pensar nuestra voluntad como libre; más bien entonces no quedaría nada más que esperar y observar qué tipo de resoluciones llevaría a efecto Dios en nosotros por medio de las causas naturales, pero no lo que por nosotros mismos, en tanto que autores podemos y debemos» (VIII, 13) *. «Podemos y debemos» - el pragmático «podemos» presupone ya la libertad y a fortiori también el deber moral-. Y a continuación el argumento que se orienta totalmente a la libertad prag-

* AA, vol. VIII, Abhandlungen nach 1781, pp. 9-14; Recension von Schulz's Versuch einer Anleitung zur Sittenlehre für alle Menschen, ohne Unterschied der Religionen, nebst einem Anhange von den Todesstrafen (N. T.). 
mática: el autor habría «presupuesto, en el fondo de su alma, aunque no quisiera confesárselo a sí mismo, que el entendimiento tiene la capacidad de determinar su juicio conforme a razones objetivas, válidas en todo momento, y que no se encuentra bajo el mecanismo de las causas que determinan de modo meramente subjetivo, que pueden cambiar en lo sucesivo, con lo cual admitió siempre la libertad de pensar, sin la cual no existiría razón alguna. Del mismo modo tiene que presuponer la libertad de la voluntad en la acción, sin la cual no existiría moral alguna» (VIII, 14). Se argumenta aquí tomando como punto de partida la necesaria autoconciencia del que juzga y actúa por sí mismo, sólo que, en el caso del autor Schulz, se ignora esta misma autoconciencia. El acto de pensar y afirmar contradice la teoría del determinismo universal sustentada con enunciados. La libertad documentada a través de la autoconciencia sería la conditio sine qua non de la razón. Kant negará en breve precisamente esto. El fundamento para ello se encuentra ya en la Crítica de la razón pura, puesto que la distinción entre fenómeno y cosa en sí, entre mundo sensible e inteligible, conduce en 1781, en contra de los textos aducidos hasta ahora, a la tesis de que o bien todo se encuentra bajo la ley de determinación de la naturaleza o bajo la ley de la libertad, tertium non datur. Pero con ello el imperativo de la pruencia se desliza fuera del dominio de la libertad; nuestro juzgar y actuar pro o contra el imperativo hipotético es cosa de la psicología y de la fisiología, pero nada tiene que ver con la libertad. Bajo el epígrafe: «Explicación de la idea cosmológica de libertad en su relación con la universal necesidad de la naturaleza» $(\mathrm{KrV}$, A 542), se habla de ello, el ser humano se conoce «también a sí mismo a través de la simple apercepción, y ello mediante actos y determinaciones internas, que no puede en modo alguno incluir en las impresiones de los sentidos. El hombre es [...] un objeto meramente inteligible» ( $K r V$, A 546); las explicaciones sucesivas abandonan, sin embargo, el terreno de la espontaneidad o de la libertad del entendimiento y localizan la libertad sólo en lo inteligible de la razón y en la causalidad de la ley moral que le es propia. La libertad está ligada, por tanto, a la ley moral y la ley moral presupone la libertad en el concepto del mundo.

En la GMS los imperativos hipotéticos pertenecen todavía al dominio de la filosofía práctica, como veíamos. La situación cambia sólo con la nítida confrontación de razón pura y razón práctica en la Crítica de la razón práctica. Aquí, como continuación de la teoría cosmológica de 1781, se equipara la libertad con la ley moral y todo lo demás se le adjudica a la naturaleza: «En suma, libertad y ley práctica incondicionada se remiten alternativamente la una a la otra» $(\mathrm{V}, 29)$. La libertad meramente «psicológica» no se diferenciaría en principio de una máquina, sería solamente un autómata espiritual, la «libertad de un asador automático» (V, 97). La prudencia, con su imperativo pragmático, es, así, una parte de lo que sucede en la naturaleza. Por muy difícil que se haga comprender esto, en particular sobre el trasfon- 
do de las explicaciones tempranas de Kant; resulta plausible, no obstante, como consecuencia del desplazamiento de la cuestión de la libertad desde la psicología a la cosmología y de la contraposición que se programa de esta suerte entre ley de la naturaleza y ley de la libertad para el «mundus sensibilis» de los fenómenos y el «mundus intelligibilis» de la moral. Es evidente que así se desmorona la unidad de la razón que se mantenía anteriormente, que, hasta 1785 inclusive, se sabía libre en la observancia de los imperativos hipotéticos y categóricos y que descubría en la conciencia práctica en general la presencia de la ley moral.

En la «Introducción» a la Crítica del discernimiento se esboza esta posición ya en el primer apartado en una autocrítica (algo velada). Habría solamente dos conceptos y con ellos dos principios, conforme a los cuales son posibles objetos, los conceptos de la naturaleza y el concepto de la libertad. Esta completa disyunción pone al descubierto un descuido que se ha mantenido hasta el momento, un gran abuso: «al identificarse lo práctico según conceptos de la naturaleza con lo práctico según el concepto de libertad» (V, 171-172). La voluntad qua causa de la naturaleza podría ser determinada mediante conceptos, del mismo modo que la materia mediante causas mecánicas y los animales mediante instintos. Los principios técnico-prácticos caerían bajo el concepto de la naturaleza, los práctico-morales bajo el concepto de la libertad. «Todas las reglas técnico-prácticas (esto es, las del arte y la destreza en general, o también las de la prudencia como destreza para influir sobre los seres humanos y sus voluntades) sólo tienen que contabilizarse como corolarios de la filosofía teórica, pues sólo atañen a la posibilidad de las cosas según conceptos de la naturaleza, a lo cual no pertenecen únicamente los medios que se encuentran al respecto en la naturaleza, sino la voluntad misma (como capacidad desiderativa y, por ende, como capacidad de la naturaleza), en tanto que puede verse determinada conforme a esas reglas por móviles de la naturaleza» $(\mathrm{V}, 172)$. En una anotación marginal en la Crítica de la razón pura (A 538) se delinea de este modo la proyección de la vida hacia la libertad: «Definiciones trascendentales: la causalidad de las representaciones de un ser con respecto a los objetos de las mismas es la vida. La determinabilidad de la facultad de representar para esta causalidad es la facultad de desear. Cuando esta facultad de representar es la razón, entonces la determinabilidad de su causalidad con respecto a los objetos, es decir, su facultad de desear, es voluntad». Y a continuación el giro decisivo: «Tiene la razón pura la causalidad, entonces la voluntad es una voluntad pura, y su causalidad se denomina libertad» (XXIII, 41). Coincide con esto una anotación en el Opus postumum: «Hay en los seres humanos un principio de la razón técnico-práctica, una relación de su voluntad a fines, los cuales, con respecto a él, son necesariamente constrictivos (neceßitantia): cuando él tiene la intención de realizar esto o aquello, entonces tiene que poner en práctica este o aquel procedimiento: el imperativo es condicionado. Sin 
embargo, en el ser humano en tanto que ser libre hay también un principio de la razón moral-práctica, que existe, de conformidad con el mismo, por antonomasia imperativa, a saber, el imperativo del deber, el cual es categórico» (XXII, 122). Solamente en este segundo respecto es el ser humano un ser libre; la razón técnico-práctica, es decir, la razón instrumental y la razón de la libertad y la moral no son idénticas.

De acuerdo con esta resolución, Kant lleva a cabo una tripartición del ser humano. Habrá que distinguir entre las disposiciones para la animalidad del ser humano en tanto que ser vivo, para la humanidad como viviente y a la vez racional y, en tercer lugar, para la personalidad en tanto que ser racional y, al mismo tiempo, responsable de sus acciones (VI, 26; cf. también 368). La frontera entre la naturaleza y la libertad discurre entre la segunda y la tercera disposición; la mencionada en la segunda posición es una razón puramente instrumental y está sometida a la determinación mediante la ley causal de la naturaleza, no de la libertad. Compárense las explicaciones correspondientes en la Crítica de la razón práctica: el ser humano «no es tan enteramente animal como para resultarle indiferente cuanto le diga la razón por sí misma [sc la razón autónoma, moral] y utilizar ésta simplemente como un instrumento para satisfacer su menesterosidad en cuanto ser sensible. Pues en absoluto elevaría su valor por encima de la mera animalidad el que posea una razón, si ésta sólo debe servirle para lo mismo que lleva a cabo el instinto entre los animales; la razón supondría entonces tan sólo una peculiar manera de la cual se habría servido la naturaleza para equiparar al ser humano en orden a un fin similar al que ha determinado para los animales, sin destinarle a él mismo hacia un fin más alto. Desde luego, conforme a lo dispuesto con él por la naturaleza, el ser humano necesita la razón para tener presente a cada momento su provecho y su perjuicio [ $s c$ el bienestar y el malestar sensible mediante la prudencia], pero la tiene además para una misión más alta, consistente no sólo en reflexionar también acerca de lo que sea bueno o malo en sí, y sobre lo cual únicamente puede juzgar la razón pura al margen de cualquier interés sensible, sino, asimismo, para distinguir por completo este juicio [sc moral] respecto de aquel otro y convertirlo en la suprema condición del mismo» (V, 61-62). La prudencia es un mero instrumento de los fines sensibles de la vida y no nos eleva con respecto a nuestro valor sobre el reino animal.

Kant es entonces consecuente si retira también la licencia de la libertad al entendimiento en general. En 1788 se dice, en el mismo sentido, que la autoconciencia sin la libertad noumenal de la moral haría del ser humano como mucho un autómata pensante: «mas la consciencia de su espontaneidad supondría simplemente un engaño si fuera tenida por libertad» $(\mathrm{V}, 101)$. «También el entendimiento forma parte de las facultades que movilizan al ser humano, además del placer, el displacer y el apetito» (XXII, 510). Esto no significa, sin embargo, que el pensar y el querer del ser solamente racio- 
nal puedan reducirse al sustrato material del cerebro. Contra esta tesis de Carl Arnold Wilmans, acerca de que el entendimiento (al contrario que la razón pura práctica) sería un ser puramente material, se dice: «Puesto que ahora la pluralidad material que no permite unidad alguna de la conciencia del sujeto no se puede unificar en el mismo sujeto y en su naturaleza con la unidad del pensamiento conforme a mis conceptos, que unifica la multiplicidad de las representaciones en una conciencia, entonces dudo poder ponerlas alguna vez sobre el mismo pie» (XII, 281-282). Esta unidad del pensamiento necesariamente inmaterial, que se requiere para la prudencia del ser racional, no puede confundirse con la apercepción trascendental de la $K r V$, puesto que es comprobable empíricamente (cf. también VII, 113); tampoco atestigua la libertad del ser racional.

Persisten problemas, entre los que es preciso mencionar algunos. Una cosa queda clara a partir de la siguiente cita de la $K r V$ de 1781: «El concepto de derecho, del que el entendimiento sano hace uso, contiene indudablemente todo lo que la especulación más sutil es capaz de desarrollar a partir de él, pero en el uso común y práctico no se tiene conciencia de las diversas representaciones incluidas en este pensamiento. Por ello no puede decirse que el concepto común sea sensible ni que contenga un mero fenómeno, ya que el derecho no puede manifestarse, sino que tenemos su concepto en el entendimiento y representa una propiedad (la propiedad moral) de las acciones, una propiedad que pertenece a éstas en sí mismas» ( $K r V$, A 43-44). Hay que separar totalmente la condición física o fenoménica de una acción de su condición moral, la primera es propia de los fenómenos, la otra de la cosa en sí misma ¿Pero cómo debe ser reconocible en general una acción como acción del lado de los fenómenos? Para las acciones, también en sentido empírico, es constitutivo el que, regidas por una regla, pongan en relación los medios con determinados fines. Ahora bien, en la Crítica de la razón pura no consta ninguna relación final entre las categorías esquematizadas o los principios; de esta manera, todo fenómeno es categorialmente indeterminable con respecto a su carácter de acción, el entendimiento no es capaz de distinguir entre una acción, sea prudente o no lo sea, y un ataque epiléptico. ¿Debe servirse el reconocimiento de una acción como acción de los medios de que dispone la dialéctica y, en 1790, la facultad de juzgar reflexionante, para el conocimiento de la finalidad en la naturaleza? ¿Dónde se encuentran los instrumentos conceptuales necesarios para pensar esta acción como acción?

Pero regresemos a la cuestión acerca de la libertad. Tras el hallazgo que hemos presentado anteriormente, las acciones de la prudencia pragmática no pueden en tanto que tales reclamar para sí libertad alguna. Ahora bien, se podría intentar colocar todos los cálculos prudenciales que el ser humano realiza bajo la alternativa moral de lo permitido o lo prohibido. Entonces el movimiento del brazo o cualquier otra expresión corporal estaría moralmente permitida bajo la condición de que no se trate, por ejemplo, de la señal 
acordada con un francotirador que está al acecho en la ventana. Todas las acciones prudenciales podrían pasar el control de la libertad y trasladarse así de la legalidad de la naturaleza a la de la libertad como noumena. Esta interpretación tendría en contra el doble concepto de mundo; mientras que en el mundo de los fenómenos todo se haya completamente determinado mediante la ley causal, en el mundo noumenal la libertad de cada acción se encuentra determinada de acuerdo con la ley moral. Cuando Kant compara la función orientadora del imperativo categórico con la de un compás (IV, 404), o su fuerza unificadora con las fuerzas newtonianas de la gravitación en el sistema planetario ( $K r V$, B XXII), estas analogías hablan de la omnipresencia de la determinación de nuestra acción mediante la ley de la libertad. Cada acción es el fenómeno de una causalidad inteligible, o sea, moral. Cada acción en general es o bien moralmente permitida o prohibida y pertenece así a la libertad determinada legalmente: «Permitida es una acción (licitum), que no se opone a la obligación; y se llama permiso (facultas moralis) a esta libertad, que no está limitada por ningún imperativo opuesto. A partir de aquí se sobreentiende lo que no está permitido (illicitum)» (VI, 222) - así suena una explicación en la «Introducción» de la Metafísica de las costumbres- ¿ ¿Se adecua con esto también la explicación que Kant proporciona de los denominados adiaphora? «Pero puede considerarse como virtud ficticia la de aquel que no admite que haya cosas indiferentes (adiaphora) desde el punto de vista moral, que siembra todos sus pasos de deberes, como de cepos, y que no considera indiferente que me alimente de carne o pescado, de cerveza o de vino, cuando ambos me son de provecho; hay aquí una micrología, cuyo dominio se convertiría en tiranía si la incluyéramos en la doctrina de la virtud» (VI, 409). Es comprensible que no pueda haber acción alguna indiferente en sí, como comer pescado o carne, porque aquel adiaphoron pertenece en primera instancia a la esfera de lo moralmente permitido y la cuestión acerca de lo permitido y lo no permitido sólo puede decidirse en relación con una ley moral de la libertad, pero no mediante la cualidad natural de una cosa cualquiera. A su vez, la decisión entre dos acciones morales permitidas tendría que ser determinada en sentido estricto a través del mecanismo de la naturaleza, en el que se localiza la mera prudencia en Kant. En la Crítica de la razón práctica se nos dice acerca de lo «permitido» y lo «no permitido» de algo diferente de lo que se dice en la Metafisica de las costumbres. Allí, en la «Tabla de las categorías de la libertad», bajo el epígrafe de la modalidad, se hace mención de «lo permitido y lo ilícito» (V, 66); pero Kant excluye explícitamente la aplicación para una diferencia solamente moral: «Así, en la tabla de las categorías de la razón práctica, bajo el epígrafe de la modalidad, lo permitido y lo ilícito (lo posible y lo imposible desde un punto de vista objetivo-práctico) casi comparten su significado con la categoría subsiguiente del deber y lo contrario al deber en el uso común del lenguaje; pero aquí lo primero debe significar aquello que se halla de acuer- 
do o en contradicción con un precepto práctico meramente posible (como, por ejemplo, la solución a todos los problemas de la geometría y de la mecánica [...] Así, por ejemplo, a un orador le resulta ilícito forjar nuevas palabras y construcciones sintácticas, pero al poeta se le permite, en cierta medida, tal licencia, sin que el deber se vea concernido en ninguno de los dos casos» (V, 11 nota) ${ }^{19}$. Con esto se cierra aquí la salida para llegar con nuestra prudencia a través de la puerta de la tabla de las categorías al reino de la libertad. Nos quedamos atascados en la psicología con sus resultados unificativos indiferentes desde el punto de vista moral.

Nos quedamos perplejos también ante el pueblo de los malvados aunque prudentes demonios, que, según el escrito Hacia la paz perpetua, son capaces de resolver el problema de la instauración del estado. Demonios «siempre que tengan entendimiento» y «una muchedumbre de seres racionales» (VIII, 366); libertad y ley moral, respeto ante la ley, una conciencia que no yerre, todo esto no les corresponde a los demonios, puesto que entonces no se distinguirían de los seres humanos, serían seres de razón y no solamente seres racionales (cf. VI, 26-27 y 368). En sus cabezas discurre todo conforme al mecanismo de la naturaleza; cuando los demonios prudentes son capaces de resolver un «problema», no de la geometría o de la mecánica, sino de la organización del estado, jugando al modo de Thomas Hobbes, entonces para ellos es finalmente tan sólo un problema de los mecanismos de la inclinación y del estado de máquinas y entendimientos, no de la república kantiana de personas libres.

En comparación con las reflexiones de 1772-1773, el campo de problemas de la libertad se ha desplazado para Kant manifiestamente. Él columbra, a lo que parece, en su evolución, que la libertad sólo es posible en estricta oposición a la legalidad natural y bajo la condición de una legalidad propia. El decurso de pensamientos en la solución de problemas matemáticos, teoréticos e incluso de teoría del estado, no se rige por ley alguna de la libertad, sino que, en último término, se puede explicar psicológicamente. La libertad, por el contrario, es cosa de la razón pura práctica y con ello exclusivamente del derecho y la virtud; no son libres los seres razonables, sino los seres de razón. La prudencia como tal no tiene ya nada - más - que ver con la libertad. Éste es uno de los niveles teóricos; en el otro rige, con la obviedad de una convicción cotidiana, que nosotros somos libres en todas nuestras acciones. Pero también en enunciados meditados es la libertad de pensar y de juzgar una obviedad. Así, en La contienda entre las Facultades (1798) figura: la razón es «la capacidad de juzgar con autonomía, esto es, libremente (conforme a los principios del pensar en general)»* (VII, 27).

\footnotetext{
19 Este pasaje no es tenido en cuenta por Bobzien (1988), que erróneamente relaciona las categorías de lo permitido y lo no permitido sólo con la libertad moral.

* En castellano se cita siguiendo la traducción de Roberto R. Aramayo, El conflicto de las Facultades, Madrid, Alianza Editorial, 2003.
} 


\section{BIBLIOGRAFÍA}

AUBENQUe, Pierre (1986): La prudence chez Aristote, París.

BITTNER, Rüdiger, y CRAMER, Konrad (eds.) (1975): Materialien zu Kants «Kritik der reinen Vernunft», Francfort en el Meno.

Bobzien, Susanne (1988): «Die Kategorien der Freiheit bei Kant», en Hariolf Oberer y Gerhard Seel (eds.), Kant Analysen Probleme, Kritik, Wurzburgo, pp. 193-220.

CiCERON (o. J.): De officiis libri tres, edición de Olaus Gigon, Zúrich.

GoETHE, Johann Wolfgang von (1887-1919): Werke, Weimar, Weimarer Ausgabe.

HeNRICH, Dieter (1975): «Die Deduktion des Sittengesetzes. Über die Gründe del Dunkelheit des letzen Abschnittes von Kants "Grundlegung zur Metaphysik der Sitten"», en Denken im Schatten des Nihilismus. Festschrift für Wilhelm Weischedel zum 70. Geburtstag, Darmstadt, pp. 55-112.

HoвBes, Thomas (1966): Leviathan oder Stoff, Form und Gewalt eines bürgerlichen und kirchlichen Staates, traducción de Walter Euchner, Neuwied.

Hume, David (1896): A Treatise of Human Nature, edición de L. A. Selby-Bigge, Oxford.

KANT, Immanuel (1900 ss.): Gesammelte Schriften (Akademie-Ausgabe), Berlín.

- (1958): De mundi sensibilis atque intelligibilis forma et principiis Über die Form und die Prinzipien der Sinnen- und Geisteeswelt, edición de Klaus Reich, Hamburgo.

HINSKE, Norbert (1989): «Die "Ratschläge der Klugheit" im Ganzen der Grundlegung. Kant und die Ethik der Griechen, 3, Abschnitt, Xenophon», en Otfried HÖFFE (ed.), Grundlegung zur Metaphysik der Sitten. Ein kooperativer Kommentar, Francfort en el Meno, pp. 131-147.

LuDWIG, Bernd (1999): «Warum es keine "hypotetischen Imperative" gibt, und warum Kants hypothetisch-gebietende Imperative keine analytische Sätze sind», en H. Klemme, B. Ludwig, M. Pauen y W. Stark (eds.), Aufklärung und Interpretation, Wurzburgo, pp. 105-124.

Rousseau, Jean-Jacques (1959 ss.): Oeuvres complètes, París.

SCHWAIGER, Clemens (1999): Kategorischer und andere Imperative. Zur Entwicklung von Kants praktischer Philosophie bis 1785, Stuttgart-Bad Canstatt.

- (2002): «Klugheit bei Kant. Metamorphosen eines Schlüsselbegriffes der praktischen Philosophie», Aufklärung, 14, pp. 147-159.

SteIGLEDER, Klaus (2002): Kants Moralphilosophie. Die Selbstbezüglichkeit reiner praktischer Vernunft, Stuttgart und Weimar.

WIEDEmanN, Conrad (2000): «Fortifikation des Geistes. Lipsius, der Cento und die prudentia civilis», en Notker HAMMERSTEIN y Gerrit WALTHER (eds.), Späthumanismus. Studien über das Ende einer kulturhistorischen Epoche, Wallstein im Taunus, pp. 183-207. 